\title{
Costo-efectividad de la detección del virus del papiloma humano en los programas de tamización de cáncer de cuello uterino
}

\author{
Aurelio Mejía ${ }^{1}$, Walter Salas ${ }^{2}$ \\ 1 Grupo de Economía de la Salud, Facultad de Ciencias Económicas, Universidad de Antioquia, Medellín, \\ Colombia \\ 2 Escuela de Microbiología, Universidad de Antioquia, Medellín, Colombia
}

La inclusión de una prueba de detección de ADN del virus del papiloma humano puede hacer más costo-efectivos los programas de tamización de cáncer de cuello uterino. No obstante, las circunstancias para lograrlo son diferentes entre países. El objetivo de este artículo es analizar la relación de costo-efectividad de incorporar la detección del virus del papiloma humano en los programas de tamización de cáncer de cuello uterino, diferenciando los resultados para países desarrollados y en desarrollo. Se hizo una revisión de los artículos publicados entre enero de 2000 y diciembre de 2006, que analizaban la relación de costo-efectividad para estrategias de tamización de cuello uterino que incluían la detección del virus del papiloma humano.

Se analizaron los resultados de 17 artículos originales y seis artículos de revisión. En los países desarrollados la inclusión de la prueba del virus del papiloma humano en los programas de tamización es costo-efectiva en la medida que acompañe la citología y se emplee para el manejo de mujeres con informe de células escamosas atípicas de significado indeterminado en la citología, se aumente el intervalo de las consultas de las mujeres en más de dos años y se realice en mujeres mayores de 30 años. Para los países en vía de desarrollo es necesario establecer primero programas organizados de tamización, y garantizar la cobertura y el acceso al diagnóstico y el tratamiento.

Palabras clave: neoplasias de cuello uterino/diagnóstico, análisis costo-beneficio, diagnóstico precoz, citología, revisión [Tipo de publicación].

\section{Cost effectiveness of human papilloma virus testing in cervical cancer screening: A literature review}

Human papilloma virus DNA testing may improve the cost effectiveness of cervical cancer screening programs. However, the circumstances to get this improvement are not the same between countries. The objective of this paper is to evaluate the cost effectiveness of introducing human papilloma virus testing in the current screening practice both in developed and developing countries. We conducted a review of published articles since January 2000 until December 2006 related to the cost effectiveness of introducing human papilloma virus testing in cervical cancer screening programs. A total of 17 original researches and six reviews were analyzed. Human papilloma virus testing is cost effective in developed countries only if it is a complementary test to Pap test and used to determine the management of women with atypical squamus cells of undetermined significance, the interval among tests is increased more than two years and it is performed in women over 30 years. On the other hand, developing countries should establish first organized screening programs and guarantee full coverage and access to diagnosis and treatment.

Key words: Uterine cervical neoplasms/diagnosis, cost-benefit analysis, early diagnosis, cytology, review [Publication type]. 
Los estudios epidemiológicos y de biología molecular han constatado una relación fuerte y específica entre la infección por el virus del papiloma humano (VPH) y el cáncer de cuello uterino, lo cual tiene importantes repercusiones prácticas, ya que permite una identificación más clara de los grupos de alto riesgo y cribarlos entre grandes grupos de población $(1,2)$.

Si se considera que el VPH juega un papel fundamental en el desarrollo del cáncer de cuello uterino, y que la manera más precisa para detectarlo y genotipificarlo son las pruebas moleculares, como la reacción en cadena de la polimerasa (PCR) o la captura de híbridos, es pertinente analizar los costos y la efectividad esperada de la utilización de estas pruebas en los programas de tamización del cáncer de cuello uterino, a partir de lo cual se aporten elementos sobre la viabilidad y utilidad de su inclusión en los programas de detección precoz del cáncer de cuello uterino, reconociendo que los países desarrollados y en desarrollo ofrecen panoramas muy diferentes que son determinantes sobre dicha viabilidad.

Dados los recientes avances en el campo de la tamización del cáncer de cuello uterino, surge la inquietud de cómo invertir los recursos disponibles y cuál debe ser la estrategia de tamización más adecuada, de manera que se maximicen los beneficios en salud al tiempo que se minimice el costo de oportunidad. La evaluación económica en salud, que se define como la estimación y comparación de los costos y las consecuencias de las opciones existentes para la consecución de un objetivo específico, es una herramienta interesante para evaluar los posibles costos y beneficios de una gran variedad de políticas $(3,4)$ con el fin de contribuir en la toma de decisiones y al mejor aprovechamiento de los recursos disponibles para la prevención y tratamiento del cáncer de cuello uterino.

\footnotetext{
Correspondencia:

Aurelio Mejía, Facultad de Ciencias Económicas, Universidad de Antioquia, Calle 67 № 53-108 oficina 13-121, Medellín, Colombia.

Teléfono: (57-4) 21958 27; fax: (57-4) 2195843

aemejiamejia@yahoo.com

Recibido: 09/02/07; aceptado: 11/10/07
}

El objetivo de este artículo es analizar la relación de costo-efectividad de la incorporación de la detección de ADN del VPH en los programas de tamización de cáncer de cuello uterino, diferenciando los resultados para los países desarrollados y en desarrollo.

\section{Materiales y métodos}

Se hizo una revisión de artículos originales o revisiones de temas que analizaran la relación costo-efectividad de la inclusión de la detección de VPH en los programas de tamización de cáncer de cuello uterino. Se efectuó la búsqueda en bases de datos (Pubmed, Medline, ScienceDirect, Econlit, Jstor, Taylor and Francis, OVID, Cochrane, Scielo Public Health, Current Contents, LILACS), así como en buscadores de internet (Scholar Google). Se restringió la búsqueda a evaluaciones económicas completas (4), publicadas en inglés o español y posteriores a enero de 2000 y hasta diciembre de 2006, sin importar el tipo de medida de efectividad empleado por el estudio. Se excluyeron los artículos que determinaban únicamente los costos o la utilidad de la prueba de VPH, que analizaban estrategias de tamización basadas en citología u otros métodos, o que estudiaban la relación entre la infección por VPH y el cáncer de cuello uterino.

Se revisaron las referencias de los artículos recuperados para identificar otros que no se encontraron en las bases de datos. De cada uno de los artículos, se destacaron la perspectiva empleada, los costos de la prueba molecular de VPH, la medida del efecto, la tasa de descuento para la actualización de los costos y beneficios futuros y la relación costo-efectividad.

Los términos empleados para la búsqueda fueron: cost effectiveness, cost utility, cost benefit, technology assessment, economic evaluation, cervical screening, HPV (human papilomavirus), cervical cancer, cytology, early diagnosis, y sus equivalentes en español. Se utilizaron los términos múltiples que describen la condición de interés y se combinaron con el operador booleano "AND" para obtener artículos más específicos. Para facilitar la comparación, los costos y relaciones de costo-efectividad se actualizaron a dólares de 2006 empleando el módulo de salud 
del índice de precios al consumidor de los Estados Unidos (5). Las cifras en otras monedas se convirtieron a dólares usando la tasa de cambio anual promedio del respectivo año y, posteriormente se actualizaron a dólares de 2006.

\section{Resultados}

Se encontraron 22 artículos que cumplían con los criterios de inclusión indicados en la metodología. Se incluyó una revisión sistemática publicada a finales de 1999 por considerarse relevante para los intereses de este artículo, además de ser uno de los estudios con mayor citación entre las publicaciones revisadas. De este modo, se analizaron los resultados de 23 trabajos, distribuidos así: 17 artículos originales y 6 artículos de revisión (cuadro 1).

En relación con la perspectiva del estudio, en los artículos originales, cuatro emplearon una perspectiva institucional y del paciente (incluían costos médicos directos y costos del paciente); siete, la perspectiva institucional o del pagador (sólo incluían los costos médicos) y seis tenían una aproximación desde el punto de vista social (costos directos e indirectos para el paciente y el sistema de salud).

Respecto a la efectividad, nueve artículos adoptaron como resultado de interés el incremento en la esperanza de vida, o años de vida salvados; tres agregaron el cálculo de años de vida ajustados por calidad (quality adjusted life years, QALY); cuatro emplearon casos detectados de neoplasia intraepitelial de cuello uterino de alto grado (2-3); y uno adoptó un enfoque de análisis costobeneficio. Diez artículos emplearon una tasa del $3 \%$ para actualizar los costos y beneficios futuros; uno, 3,5\%; uno, 6\%; dos sólo actualizaron los costos a unas tasas de $5 \%$ y $3 \%$, y tres artículos no realizaron ninguna actualización. Por otra parte, 15 artículos hicieron el análisis de sensibilidad y dos no especifican. Finalmente, 10 artículos emplearon (o usaron datos de) la prueba Hybrid Capture II de Digene Corporation para realizar el test del VPH, dos la versión Hybrid Capture I y cinco no especifican la prueba empleada.

Las principales opciones para el uso de la detección del virus son: 1) adicional a la citología convencional (o a la citología en base líquida) para mejorar la sensibilidad, 2) para manejar mujeres con reporte de células escamosas atípicas de significado indeterminado en la citología y mejorar la especificidad, 3) como única alternativa para la tamización, y 4) para el seguimiento posterior al tratamiento de lesiones de alto grado para verificar su éxito $(23,28-30)$.

Los costos de utilizar la prueba de detección deL VPH se reportan en el cuadro 2. Los factores que inciden sobre el costo del programa al incluir la detección de VPH están asociados, además del costo de la prueba, con el personal involucrado en la recolección y procesamiento de las muestras y pruebas de laboratorio, así como el costo del seguimiento de mujeres asintomáticas con resultado positivo para VPH (12).

Entre los principales beneficios que justifican el uso de la prueba de VPH, se encuentra la reducción de la morbimortalidad asociada al cáncer de cuello uterino como resultado del tratamiento precoz, la disminución de los costos totales al permitir una ampliación del tiempo entre pruebas y los menores costos de tratamiento para casos que no arriesguen la vida o regresen a estados normales (23). En el cuadro 3 se reportan la sensibilidad y especificidad de la citología y de la prueba del VPH, así como la estrategia combinada. Se observa que, en general, la citología tiene una mayor especificidad que la prueba del VPH o la estrategia combinada, aunque con una sensibilidad bastante inferior. Por su parte, el test del VPH es un indicador más sensible para neoplasia intraepitelial de cuello uterino de alto grado que la citología convencional o líquida. La estrategia combinada tendría una sensibilidad y unos valores diagnósticos negativos de casi el $100 \%$, con una ligera reducción en la especificidad respecto a la citología, pero ello se compensaría por la mayor protección contra la progresión a neoplasia y el ahorro de recursos derivado del mayor intervalo de tamización.

En el cuadro 4 se presentan las relaciones de costo-efectividad de los artículos originales. En los países en desarrollo, el costo por año de vida ganado de incluir la prueba del VPH es muy sensible al intervalo entre consultas; por ejemplo, 
Cuadro 1. Resumen de los artículos revisados

\begin{tabular}{lll}
\hline Artículo & Aplicación & Conclusiones \\
\hline Goldie (6), 2001 & Estados Unidos & $\begin{array}{l}\text { Adicionar la prueba de VPH para las dos primeras citologías en el año siguiente } \\
\text { al diagnóstico del VIH, modificando los posteriores intervalos de la citología } \\
\text { (cada seis meses para quienes se detecte ADN de VPH y anualmente para el } \\
\text { resto), parece ser una modificación costo efectiva de la práctica actual (citología } \\
\text { anual) en las mujeres infectadas con VIH en Estados Unidos. }\end{array}$
\end{tabular}

Goldie (7), $2001 \quad$ Sudáfrica Las estrategias de tamización de cuello uterino basadas en la inspeción visual o detección de ADN de VPH, eliminan colposcopia y son alternativas atractivas a los programas basados en la citología en lugares de bajos ingresos.

Gamzu (8), $2002 \quad$ Israel La detección de VPH es clínica y económicamente más beneficiosa que la citología debido a su mejor sensibilidad, especificidad y valores pronóstico positivos.

Kim (9), $2002 \quad$ Estados Unidos Tamización cada dos o tres años basado en citología líquida y test de VPH para el manejo de mujeres con reporte de (atypical squamous cells of unde termined significance) (células escamosas atípicas de significado indeterminado) (ASC-US) es más efectivo y menos costoso que la citología convencional anual.

Mandelblatt (10), 2002 Tailandia

La alternativa más costo-efectiva es la inspección visual cada cinco años con tratamiento inmediato si se detectan lesiones. La detección de VPH tiene resultados similares si la prueba cuesta menos de US $\$ 6$ y el $90 \%$ de las mujeres que tienen resultados anormales siguen tratamiento. La citología es una buena alternativa si la sensibilidad es superior al $80 \%$ y el $90 \%$ de las mujeres que tienen resultados anormales siguen tratamiento. La combinación de Pap y VPH cada cinco años alcanza una reducción de más del $90 \%$ de la mortalidad por por cáncer de cuello uterino, a un costo de US\$2.170 por año de vida ganado.

Duttagupta (11), 2002 India La detección de VPH debe realizarse en las mujeres menores de 23 años con alguna lesión de cuello uterino, y como estrategia adicional a la citología en las mujeres de 24 a 43 años. Para las mayores de 44, la detección de VPH puede no ser útil, debido al descenso en la prevalencia de infección por VPH a partir de esta edad.

Mandelblatt (12), 2002 Estados Unidos La estrategia de citología y VPH salva años de vida adicionales a un costo razonable comparada con sólo citología. Sin importar la modalidad, las mayores ganancias en salud de la tamización dependen de que se logre la mayor cobertura posible y se garantice el acceso al diagnóstico y al tratamiento.

Mittendorf (13), 2003 Alemania

Las estrategias que incorporan detección de VPH son superiores a la citología y a las medidas actuales en Alemania, pues presentan menores costos y salvan más años de vida. Por tanto, la detección de VPH debería convertirse en un componente esencial para aumentar la relativamente baja sensibilidad de los procedimientos actuales.

Lytwyn (14), $2003 \quad$ Canadá La citología combinada con el test de VPH es más costosa pero puede detectar más casos de neoplasia intraepitelial de cuello uterino 2,3 que la citología. No obstante, el pobre cumplimiento limita la utilidad de manejar esta estrategia que requiere seguimiento $y$, por consiguiente, exámenes a repetición.

Goldie (15), 2004 Estados Unidos Para mujeres mayores de 30 años, la tamización cada dos o tres años con detección de VPH adicional a la citología o sólo para mujeres con reporte de ASC-US, proporciona una mayor reducción en el cáncer de cuello uterino, y es menos costoso que la citología anual convencional. La combinación de citología y detección de VPH como estrategia anual proporciona ganancias muy pequeñas en términos de años de vida con unos costos muy elevados.

Sherlaw (16), $2004 \quad$ Reino Unido Las relaciones de costo-efectividad de estrategias que introducen la citología en base líquida son favorables. Pero si el costo marginal respecto a la práctica actual es elevado, es preferible no incorporar la citología en base líquida. Las estrategias basadas en la detección del VPH tienen un mayor riesgo de colposcopias innecesarias.

Kim (17), 2005

Reino Unido, Las relaciones de incremento de costo-efectividad para las estrategias combinadas Holanda, Francia están en el rango de US\$10.625-82.288 por año de vida ganado, según el 
e Italia

Legood (18), $2005 \quad$ India

Goldie (19), 2005

Bidus (21), 2006

Kulasingam (22), 2006 Estados Unidos

Cuzick (23), 1999 Revisión

Goldie (24), $2002 \quad$ Revisión

Goldie (25), 2003 Revisión

Holmes (26), 2005 Revisión

Goldie (27), $2006 \quad$ Revisión

Goldie (3), $2006 \quad$ Revisión Kenya, Perú udáfrica y el intervalo del tamización. La detección de VPH tiene el potencial de incrementar los beneficios en salud a un costo razonable comparado con las políticas actuales de tamización en esos cuatro países europeos.

El costo promedio por cada 1.000 mujeres elegibles para tamizar fue de US\$ 4.611, US $\$ 7.780$ y US $\$ 13.866$ para la inspección visual, citología y detección de VPH. La detección de VPH puede no ser una estrategia costo-efectiva en India a los precios actuales, dado que es similar a la citología en cuanto a casos detectados pero a un costo mucho mayor.

Las estrategias más efectivas son las que implican un menor número de visitas. Realizar una inspección visual del cuello uterino con ácido acético o realizar la prueba de VPH una vez en la vida, reduce el riesgo vital de cáncer de cuello uterino,entre $25 \%$ y $36 \%$, a un costo de menos de US\$ 645 por año de vida ganado.

La detección de VPH para el manejo de todas las mujeres con anormalidades citológicas de bajo grado (colposcopia para resultado positivo y seguimiento con citología para negativo), es probablemente una estrategia costo-efectiva bajo los protocolos actuales del Reino Unido, aunque el incremento en el número de colposcopias requiere consideración detallada.

Estados Unidos En las mujeres en servicio activo en la U.S. Army, la detección de cáncer de cuello uterino,con citología en base líquida y detección de VPH para mujeres con reporte de ASC-US, realizada cada dos años, es costo-efectiva, en especial cuando se consideran los costos indirectos.

Comparado con repetición de la citología y empleando la lesión intraepitelial de alto grado como umbral para la remisión a colposcopia, el uso de la prueba de VPH tiene un costo de $\$ 3.813$ por caso de NIC 3 detectado.

La detección de VPH tiene tres usos potenciales en los programas de tamización de cáncer de cuello uterino: 1) como estrategia adjunta a la citología para mujeres mayores de 30 o 35 años, 2) manejo de mujeres con anormalidades citológicas menores; 3) seguimiento al tratamiento de neoplasia intraepitelial de cuello uterino de alto gradopara determinar más precisa y rápidamente si se ha eliminado completamente la enfermedad.

Ejemplos para Estados Unidos y Sudáfrica ilustran las ganancias y sacrificios que se obtienen cuando se debe escoger entre varias políticas para disminuir la mortalidad por cáncer de cuello uterino,y demuestran cómo los modelos matemáticos pueden facilitar un puente entre la investigación y la política de salud.

Recientes avances dan la oportunidad de revisar las estrategias actuales de tamización de cuello uterino. Cómo invertir los recursos para maximizar los beneficios en salud y minimizar el costo de oportunidad, es una cuestión crítica. El análisis de costo-efectividad y el modelo puede ser una herramienta interesante para evaluar los posibles costos y consecuencias de una gran variedad de políticas.

A pesar de las diferencias en las estrategias que incluyen detección de ADN de VPH, el costo por año de vida ajustado por calidad (QALY) se encuentra siempre en el rango de US\$15.985-20.626. La combinación de detección de VPH con citología para mujeres mayores de 30 parece ser costo-efectiva. En países con programas establecidos, el análisis de alternativas de prevención secundaria del cáncer de cuello uterino, se ha centrado en determinar el intervalo óptimo de tamización, edad de inicio y fin y cómo mejorar la citología. En situaciones más precarias se ha analizado cómo incrementar el vínculo entre tamización y tratamiento y analizar la posibilidad de implementar estrategias alternativas a la citología.

Los modelos matemáticos permiten integrar la mejor información para identificar los factores que más probablemente afectan los resultados de las diferentes estrategias de tamización de cáncer de cuello uterino, además de orientar el diseño de futuras investigaciones y proporcionar información acerca de las posibles relaciones de costo-efectividad que asistan el proceso de toma de decisiones. 
Cuadro 2. Costo de utilizar la prueba del virus del papiloma humano en países desarrollados y en vía de desarrollo.

\begin{tabular}{lll}
\hline Países desarrollados & Costo & Observaciones \\
\hline Estados Unidos (12) & 39 & Sin consulta \\
Estados Unidos (9) & 63 & Sin consulta \\
Estados Unidos (21) & 38 & Sin consultaoficial \\
Estados Unidos (3) & 103 & Incluye costos de personal, equipos y tiempo de visita \\
Reino Unido (17) & 46 & Incluye costos de personal, equipos y tiempo de visita \\
Reino Unido (3) & 97 & Incluye costos de personal, equipos y tiempo de consulta \\
Reino Unido (16) & 39 & Incluye costos de personal, equipos y tiempo de consulta \\
Holanda (17) & 49 & Incluye costos de personal, equipos y tiempo de consulta \\
Holanda (3) & 129 & Incluye costos de personal, equipos y tiempo de consulta \\
Francia (17) & 34 & Incluye costos de personal, equipos y tiempo de consulta \\
Francia (3) & 45 & Incluye costos de personal, equipos y tiempo de consulta \\
Italia (17) & 35 & Incluye costos de personal, equipos y tiempo de consulta \\
Italia (3) & 90 & Incluye costos de personal, equipos y tiempo de consulta \\
Reino Unido (20) & $37(19-62)$ & Incluye personal y equipos \\
Alemania (13) & 26 & Sin consulta \\
\hline Países en desarrollo & Costo & Observaciones \\
\hline Sudáfrica (19) & 52 & Incluye personal, equipos y consulta \\
Sudáfrica (7) & 11 & Costos directos \\
Perú (19) & 39 & Incluye personal, equipos y consulta \\
Kenia (19) & 28 & Incluye personal, equipos y consulta \\
Tailandia (19) & 18 & Incluye personal, equipos y consulta \\
India (19) & 15 & Incluye personal, equipos y consulta \\
India (18) & 14 & Perspectiva institucional. Incluye gastos de personal y equipos y consulta. \\
India (11) & 7 & Valor aproximado \\
Tailandia (10) & 39 & Costos directos de personal pero sin consulta \\
\hline
\end{tabular}

en Sudáfrica, la realización de la prueba cada tres años quintuplica el costo por año de vida ganado comparado con una estrategia de tres consultas en toda la vida. En los países desarrollados, por lo general, el costo por año de vida ganado no supera los US\$50.000, excepto para algunas estrategias en Estados Unidos hasta edades muy avanzadas o con intervalos muy reducidos. Los factores que más inciden sobre las relaciones de costo-efectividad de la inclusión del test del VPH son la edad de inicio y finalización de la tamización, el intervalo entre pruebas y la población a la que se aplica la prueba (todas las mujeres, las mayores de 30, o las mujeres con reporte de ASCUS en la citología).

Inclusión de la prueba del virus del papiloma humano en los países desarrollados

En los países desarrollados, por lo general, se cuenta con un programa establecido de tamización de cáncer de cuello uterino basado en la citología.
Los estudios proporcionan evidencia de la racionalidad clínica del uso de la prueba del VPH de manera conjunta con la citología, en tanto las mujeres infectadas con tipos oncogénicos de este virus constituyen un grupo de alto riesgo que amerita un mayor seguimiento (31), pero al mismo tiempo, surgen cuestionamientos sobre la viabilidad financiera de implementar las estrategias sugeridas.

Una revisión sistemática de varios artículos que modelan la historia natural del cáncer de cuello uterino y el impacto de diversas estrategias de tamización (26), concluye que existe un consenso respecto al valor de las relaciones de costoefectividad de estrategias que emplean la detección del VPH, las cuales se encuentran significativamente por debajo del valor límite generalmente aceptado de US\$50.000 por año de vida ganado. A pesar de las diferencias en los modelos, todas las estrategias que involucran el test del VPH cuestan entre US\$15.985 y US\$ 
Cuadro 3. Sensibilidad y especificidad de alternativas para tamización de cáncer de cuello uterino.

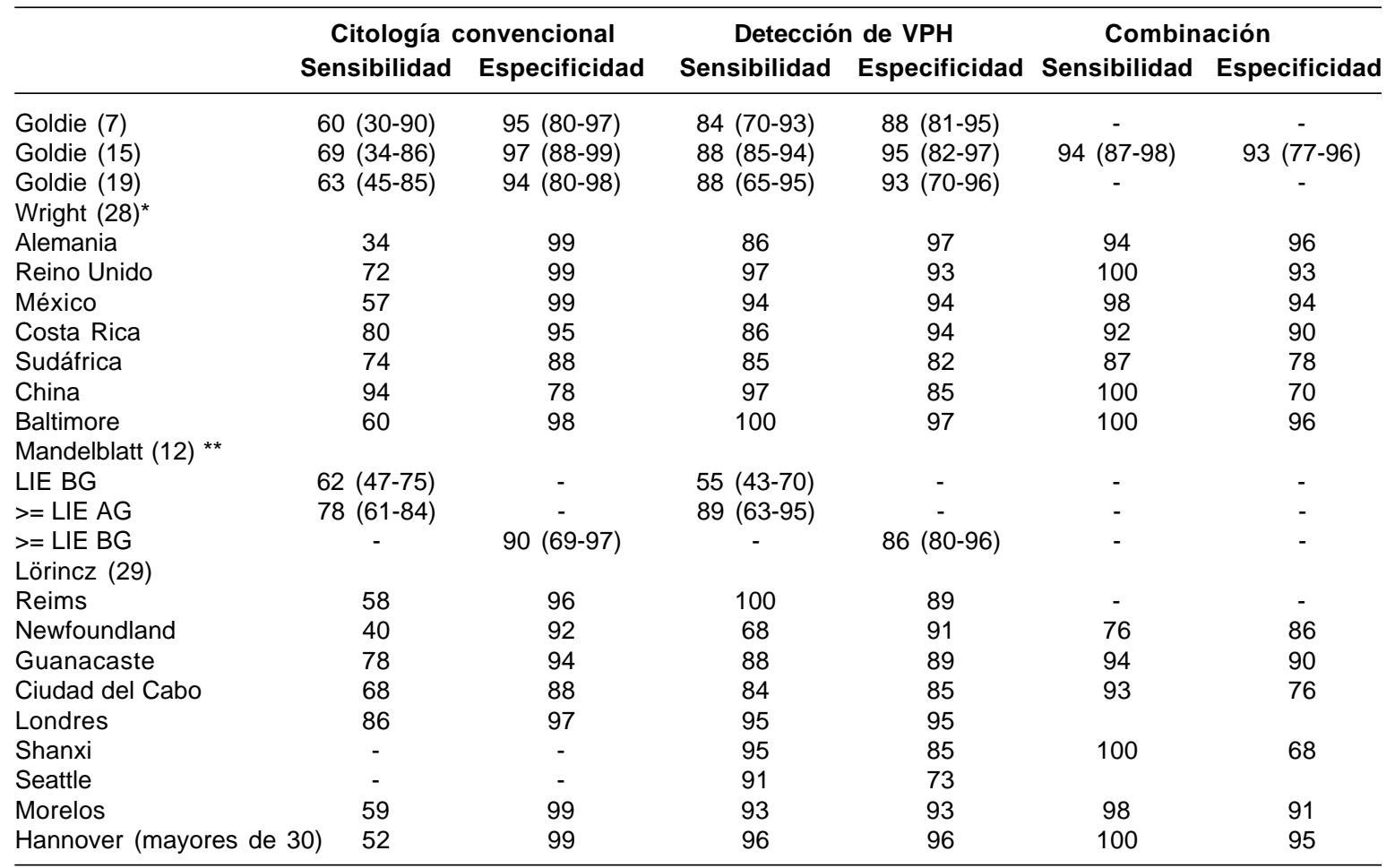

* Para ¿NIC? II o superior

${ }^{* *}$ Considerando ASC-US como resultado negativo. LIE AG = lesión intraepitelial de alto grado. LIE BG = lesión intraepitelial de bajo grado.

20.626 por QALY (sin ajustes por calidad, el valor más alto es de US\$24.810 por año de vida ganado).

Mandelblatt et al. (12) encuentran que los mayores beneficios en términos de reducción en la incidencia y mortalidad del cáncer de cuello uterino se obtienen con una tamización cada dos años que combina citología y detección del VPH, con un costo de US\$98.208 por QALY. La combinación de citología y detección del VPH reporta la mayor reducción en el número de cánceres invasores, pero con el riesgo de un mayor uso de colposcopia para la evaluación de falsos positivos y para el diagnóstico de mujeres en quienes se detecte neoplasia intraepitelial de cuello uterino. Las estrategias que incluyen solamente detección del VPH se encuentran dominadas por otras, pero si el costo de la prueba del VPH es inferior a US\$6, dicha estrategia es la más costo-efectiva y justifica su uso como estrategia primaria en la tamización. Sin embargo, para que la detección del VPH pueda convertirse en el único método de tamización, especialmente para mujeres mayores de 30 años, se requiere evidencia de una alta sensibilidad para las lesiones de alto grado que progresan a cáncer (23).

En relación con la edad para aplicar la prueba, se ha demostrado que es poco útil emplearla en mujeres cercanas a los 20 años de edad, pues, si bien en esta edad la sensibilidad del test es mayor, una gran proporción elimina la infección (32). En cuanto a la edad límite, se encuentra que casi todos los beneficios se logran cuando se realiza la prueba hasta los 60 a 65 años (27).

Son varios los estudios que afirman que la combinación del test de ADN del VPH y el Papanicolau traería resultados saludables, con 
Cuadro 4. Costo-efectividad de la inclusión de la prueba del virus del papiloma humano en los programas de tamización de cuello uterino.

\begin{tabular}{|c|c|c|}
\hline Países desarrollados & Costo/efectividad* & Observaciones \\
\hline Estados Unidos (12) & 90.685/QALY & VPH y citología cada dos años hasta los 75 \\
\hline Estados Unidos (9) & $76.831 /$ YLS & VPH para ASC-US más citología en base líquida cada tres años \\
\hline Estados Unidos (15) & $38.205 / / Y L S$ & $\begin{array}{l}\text { Citología convencional hasta los } 30 \text { años y adición de VPH después } \\
\text { de esta edad. Pruebas cada cuatro años }\end{array}$ \\
\hline Estados Unidos (21) & $5.573 / Y L S$ & Citología en base líquida + VPH cada tres años Vs. sin tamización \\
\hline Estados Unidos (6) & 13.416-18.782/QALY & $\begin{array}{l}\text { Para mujeres infectadas con VIH, citología cada seis meses para } \\
\text { aquellas con infección por VPH y anual para el resto. Se compara } \\
\text { con no tener tamización. }\end{array}$ \\
\hline Estados Unidos (22) & 3.813/NIC adicional & VPH para manejo de mujeres con reporte de ASC-US \\
\hline Reino Unido (16) & $6.608 / Y L S$ & Citología en base líquida + VPH cada cinco años \\
\hline Reino Unido (20) & $6.634 / Y L S$ & $\begin{array}{l}\text { VPH + citología en base líquida para mujeres con ASC-US oLIE } \\
\text { de bajo grado Vs. citología }\end{array}$ \\
\hline Reino Unido (17) & 14.961/YLS & $\begin{array}{l}\text { Citología hasta los } 30 \text { años con adición de VPH para mayores. } \\
\text { Tamización cada cinco años }\end{array}$ \\
\hline Alemania (13) & $60 / Y L S$ & Se compara contra no tener tamización. \\
\hline Holanda (17) & $35.452 / Y L S$ & $\begin{array}{l}\text { Citología hasta los } 30 \text { años con adición de VPH para mayores. } \\
\text { Tamización cada cinco años }\end{array}$ \\
\hline Francia (17) & $28.514 /$ YLS & $\begin{array}{l}\text { Citología hasta los } 30 \text { años con adición de VPH para mayores. } \\
\text { Tamización cada tres años }\end{array}$ \\
\hline Italia (17) & 10.625/YLS & $\begin{array}{l}\text { Citología hasta los } 30 \text { años con adición de VPH para mayores. } \\
\text { Tamización cada cinco años }\end{array}$ \\
\hline Canadá (14) & 2.763/NIC adicional & $\begin{array}{l}\text { Combinación de detección de VPH y citología para mujeres con } \\
\text { ASC-US o LSIL }\end{array}$ \\
\hline Israel (8) & 1.796/NIC adicional & $\begin{array}{l}\text { Se remiten a colposcopia las mujeres con lesión intraepitelial de } \\
\text { bajo y alto grado, y las de resultado normal con VPH positivo }\end{array}$ \\
\hline Países en desarrollo & Costo/efectividad & Observaciones \\
\hline India (18) & 1.645/NIC adicional & $\begin{array}{l}\text { Detección de VPH Vs. no tamización, pero es más costoso y } \\
\text { menos efectivo que la citología }\end{array}$ \\
\hline Sudáfrica (7) & 15.428/YLS & $\begin{array}{l}\text { Test de VPH cada tres años. Cuesta US } \$ 52 / \text { YLS para una sola } \\
\text { tamización a los } 35 \text { años }\end{array}$ \\
\hline India (19) & $762 / Y L S$ & Tres consultas con VPH Vs. la mejor estrategia siguiente \\
\hline Kenia (19) & $1.430 /$ YLS & Tres consultas con VPH Vs. la mejor estrategia siguiente \\
\hline Perú (19) & $1.476 / Y L S$ & Tres consultas con VPH Vs. la mejor estrategia siguiente \\
\hline Sudáfrica (19) & 3.169/YLS & Tres consultas con VPH Vs. la mejor estrategia siguiente \\
\hline Tailandia (19) & 848/YLS & Tres consultas con VPH Vs. la mejor estrategia siguiente \\
\hline Tailandia (10) & $2.170 / Y L S$ & Combinación de citología y VPH cada 5 años \\
\hline India (11) & Beneficio neto $=1.121 .214$ & $\begin{array}{l}\text { Valor presente del beneficio neto para una cohorte de } 100 \text { mujeres } \\
\text { tamizadas desde los } 23 \text { hasta los } 43 \text { años, con una combinación } \\
\text { de detección de VPH y citología. En los beneficios sólo considera } \\
\text { las ganancias salariales. }\end{array}$ \\
\hline
\end{tabular}

*: QALY: año de vida ajustado por calidad; YLS: año de vida salvado.

beneficios para los pacientes, los médicos y el sistema de salud. Se puede esperar una reducción importante de los falsos negativos, las pacientes con doble negativo pueden ampliar con seguridad el intervalo entre las pruebas hasta por cinco años (32) y aquéllas que se identifiquen como de alto riesgo sin enfermedad detectable pueden ser vigiladas más de cerca (29). Esos resultados son consecuentes con los encontrados en un estudio realizado en Portland (31), en el cual se asegura que un doble negativo de Papanicolau y VPH es un mejor indicador contra el riesgo futuro de neoplasia intraepitelial de cuello uterino de alto grado que tres citologías negativas consecutivas. Así mismo, una alta asistencia de las mujeres a los programas de detección temprana del cáncer 
de cuello uterino o una alta sensibilidad producirán intervalos más largos entre pruebas y simultáneamente ampliará el rango de edad más favorable en términos de costo-efectividad (33).

Por otra parte, la detección del VPH también puede emplearse para el manejo de mujeres con reporte de ASC-US $(9,14,20,21,34,35)$. Para los Estados Unidos, las estrategias más costo-efectivas en presencia de ASC-US son las que combinan la detección del VPH y citología líquida. Una estrategia bianual usando citología líquida combinada con detección de ADN del VPH para mujeres con reporte de ASC-US (colposcopia sólo si se detectan tipos de dicho virus de alto riesgo) es más efectiva y menos costosa que la citología convencional anual combinada con colposcopia o la repetición de la citología.

Sin embargo, el costo de US\$224.563 por año de vida es alto si se compara con los resultados reportados por otros estudios, por lo que se plantea como alternativa más costo-efectiva el mismo procedimiento pero cada tres años (US\$ 77.347 por año de vida ganado), aunque los autores aseguran que modificar la práctica actual (citología convencional con repetición para ASCUS) por la estrategia bianual ahorraría más de US\$ 15.000 millones durante el periodo vital de una cohorte de mujeres típica de 18 a 24 años en este país (9). Sin embargo, advierten Melinkow y Birch (35) que, si bien se ha demostrado que ésta es una estrategia costo-efectiva comparada con otras alternativas, los costos totales de llevarla a cabo pueden ser muy altos.

Finalmente, es posible el uso de la detección del VPH en el seguimiento posterior al tratamiento de neoplasia intraepitelial de cuello uterino de alto grado para determinar más precisa y rápidamente si el tratamiento ha eliminado completamente la enfermedad (23), pero el deficiente cumplimiento de los programas de tamización por parte de las mujeres limita la utilidad de esta estrategia $(14,32,33,36)$.

\section{Contexto en los países en desarrollo}

Al evaluar la relación costo-efectividad de varias estrategias en los países en desarrollo, Goldie et al. (7) afirman que, si bien las estrategias basadas en la inspección visual o detección del VPH cada tres años son eficientes en tanto permiten reducir la mortalidad por cáncer de cuello uterino, la mayoría tenían relaciones de costo-efectividad superiores a los umbrales aceptables de los países pobres. Por tal motivo, se consideraron estrategias de una consulta, y se encontró que para las mujeres surafricanas una consulta con inspección visual o detección del VPH (con crioterapia inmediata para aquéllas con resultados positivos) reducía la incidencia de cáncer de cuello uterino entre $26 \%$ y $32 \%$, a un costo de menos de US\$ 67 por mujer.

En un estudio más reciente y que abarca más países (India, Kenya, Perú, Sudáfrica y Tailandia) (19), se encontró que las estrategias más efectivas son las que implican un menor número de consultas, lo que resulta en un mejoramiento de la tamización, seguimiento y tratamiento. La realización de una inspección visual del cuello uterino con ácido acético o el realizar la prueba del VPH una vez en la vida, reduce el riesgo vital de cáncer de cuello uterino entre $25 \%$ y $36 \%$, a un costo de menos de US\$ 645 por año de vida ganado. El riesgo relativo de cáncer de cuello uterino declina un $40 \%$ adicional con dos consultas (a los 35 y los 40 años) con un costo por año de vida ganado inferior al PIB per cápita de cada país, resultado costo-efectivo según la Comisión de Macroeconomía y Salud. Estas estrategias son alternativas costo-efectivas al programa tradicional de citología de tres visitas en países de bajos recursos.

En un estudio llevado a cabo en Tailandia (10) se encontró que todas las estrategias de detección, ya fuera inspección visual, test de Papanicolau, prueba de VPH o sus combinaciones, salvaban vidas a un costo entre $\$ 156$ y $\$ 8.663$. La alternativa más costo-efectiva es la inspección visual cada cinco años con tratamiento inmediato si se detectan lesiones. La detección del VPH tiene resultados similares si la prueba cuesta menos de US\$ 6 y el $90 \%$ de las mujeres que tienen resultados anormales siguen tratamiento. La citología es una buena alternativa si la sensibilidad es superior al $80 \%$ y el $90 \%$ de las mujeres que tienen resultados anormales siguen tratamiento, aunque Kim et al. (36) sugieren que 
con una sensibilidad mayor o igual al $70 \%$, la citología convencional puede ser más costoefectiva que la citología de base líquida a intervalos de cinco años. Por su parte, la combinación de Papanicolau y detección del VPH cada cinco años alcanza una reducción de más del $90 \%$ de la mortalidad por cáncer de cuello uterino a un costo de US\$2.170 por año de vida ganado.

Por su parte, un esquema costo-efectivo en India consistiría en la detección del VPH en mujeres menores de 23 años que presenten alguna lesión de cuello uterino y de manera adjunta a la citología para todas las mujeres entre 24 y 43 años, mientras que en mayores de 44 no se recomienda la aplicación del test dado que para este grupo era más sensible la citología (11). Además, la combinación del test del VPH y la citología para todas las mujeres puede resultar muy costosa; Legood et al. (18) afirman que la detección del VPH puede no ser una estrategia costo-efectiva en India a los precios actuales, dado que es similar a la citología en cuanto a casos detectados pero a un costo mucho mayor.

En este sentido, se reconoce que la viabilidad de la implementación de la prueba del VPH en países de bajos ingresos depende en gran medida del costo de la prueba, su sensibilidad y de la organización del programa de tamización. Así, se sugiere que en los países con recursos escasos la prioridad debe ser que las mujeres sean tamizadas al menos una vez, al tiempo que se asegura que existen rendimientos decrecientes de una mayor frecuencia en la tamización (23).

\section{Discusión}

El cáncer de cuello uterino se ha reducido en muchos países a causa de la existencia de programas organizados de detección precoz, aunque éstos no son igualmente accesibles a todos los grupos de mujeres $(25,27)$. De esta manera, mientras las mujeres no accedan a los programas de detección precoz, la estrategia siempre tendrá una efectividad limitada, aun cuando se utilicen técnicas más sensibles. Así, son varios los estudios que concluyen que es más eficiente aumentar el número de años de vida ganados a través de una alta cobertura de las mujeres incluidas en grupos de edad de alto riesgo que aumentar el segmento de edad de la población o acortar el intervalo de detección (37-39). Además, sin importar la modalidad, las mayores ganancias en salud de la tamización dependen de que se logre la mayor cobertura posible y se garantice el acceso al diagnóstico, en caso de resultados anormales, y al tratamiento, si los resultados indican malignidad $(12,24)$.

Así mismo, aunque el análisis de costoefectividad puede ayudar a ilustrar las disyuntivas de diferentes alternativas de vigilancia, sólo es un insumo en la toma de decisiones. En el caso de las estrategias de tamización de cáncer de cuello uterino los aspectos cualitativos son también muy importantes: por ejemplo, comprender el comportamiento de las mujeres frente al programa y su reacción a los resultados, debe tenerse en cuenta en el momento de analizar la factibilidad de incorporar la prueba de VPH, ya que sólo unas pocas mujeres positivas para VPH desarrollan cáncer y dicha información supone una carga sicológica y un posible estigma.

Pareciera ser que la discusión en los países desarrollados es alrededor de las pruebas de detección y cómo mejorar su efectividad debido a que la accesibilidad a la citología convencional es un problema superado, pues la reducción en la incidencia de cáncer de cuello uterino a la que hacen referencia Goldie (25) y Kim et al. (9) se debe a la existencia de programas organizados de detección basados en citología convencional. En cambio, en países en desarrollo los problemas están más asociados a deficiencias en la calidad, cobertura y seguimiento, los cuales no sólo se deben a la carencia de recursos sino también a la falta de voluntad política (40).

Las estrategias de detección de cáncer de cuello uterino basadas en la inspección visual o detección del VPH, que eliminan las colposcopias y reducen el número de consultas, son una alternativa atractiva a los programas basados en la citología en los países con bajos recursos. Además, dado que la detección del VPH puede realizarse en muestras recogidas por las propias mujeres, se podría mejorar la cobertura de los programas actuales y eliminar posibles barreras culturales respecto a la toma de muestras 
vaginales para pruebas de Papanicolau o VPH de las mujeres de los países en desarrollo. En los países en desarrollo, la selección entre citología, prueba del VPH e inspección visual depende de la habilidad de los programas de relacionar tamización y tratamiento en el menor número de consultas y de los costos de las estrategias (27).

En los países desarrollados hay consenso en diferentes artículos sobre la conveniencia de utilizar la detección del VPH en intervalos de tres a cinco años, en mujeres mayores de 30 años, garantizando la asistencia de toda la población objetivo al programa de tamización, y como estrategia para definir el manejo de mujeres con reporte de ASC-US $(13,15,17,28)$ y para la tamización de mujeres con diagnóstico de VIH (6). Su uso de manera adjunta a la citología para la tamización de todas las mujeres es cuestionable, dado el alto riesgo de colposcopias innecesarias $(19,27)$.

El cáncer de cuello uterino es la principal causa de mortalidad por cáncer en las mujeres en Colombia, e incorporar la prueba molecular del VPH en los programas de tamización de este cáncer, bajo las condiciones actuales de funcionamiento, es poco costo-efectivo. En Colombia, los programas tienen dificultades para lograr una amplia cobertura, hacer seguimiento y focalizar las mujeres con mayor riesgo, pues la citología cervicouterina está dirigida a mujeres entre 25 y 65 años (41) lo que limita el acceso a un grupo de mujeres que tempranamente inicia su actividad sexual, como es el caso de las mujeres entre 25 y 49 años de edad, de las cuales $66 \%$ tuvo su primera relación sexual antes de los 20 años (42). Esta situación se ve agravada por la dificultad para hacer el seguimiento de las mujeres que se hacen la citología: $31 \%$ de las mujeres que tuvieron un resultado anormal no vuelve a una nueva consulta o para el tratamiento (42). En ese sentido, la adición de la prueba del VPH debe ir precedida por una mejora en el acceso de los programas de tamización, un aumento en la cobertura y el seguimiento a las mujeres que se hacen una citología.

La principal limitación del estudio se refiere al sesgo de publicación, que se define como la predilección editorial por publicar resultados particulares, en especial, los positivos $(43,44)$. El sesgo que surge por incluir sólo artículos publicados se trató de controlar mediante una amplia búsqueda en internet, además de las bases de datos científicas, y el contacto con varios autores destacados en el tema, y no se encontraron fuentes adicionales. El sesgo por omitir resultados en otros idiomas diferentes a inglés o español parece no ser de gran importancia en este caso, pues en su mayoría las investigaciones son publicadas en inglés. Además, se verificó que en los artículos originales no se encontraran trabajos duplicados para evitar errores en la estimación de los resultados. Finalmente, a pesar de que en la literatura científica se reconoce la presencia del sesgo de publicación, no se ha publicado un trabajo que compruebe que por este sesgo se haya cometido un error grave (43) y los análisis de sensibilidad de los trabajos revisados permiten inferir bajo qué condiciones el uso de la prueba del VPH deja de ser costo-efectiva.

\section{Agradecimientos}

Este artículo es un producto de la investigación "Estudio de costo efectividad de tres estrategias de tamizaje en la vigilancia epidemiológica de cáncer cervicouterino y lesiones premalignas en la zona nororiental de la ciudad de Medellín", en la cual participaron Marleny Valencia y Lucía Tamayo del Grupo de Citología Ginecológica y Prevención del Cáncer Cervicouterino, y Jairo Humberto Restrepo del Grupo de Economía de la Salud de la Universidad de Antioquia.

\section{Conflicto de intereses}

Los autores del artículo hacen constar que no existe, de manera directa o indirecta, ningún tipo de conflicto de intereses financieros, académicos o personales que puedan poner en peligro la validez de lo comunicado.

\section{Financiación}

Esta investigación fue cofinanciada por la Secretaría de Salud de Medellín y la Universidad de Antioquia (Convenio interadministrativo 4800000875 de 2005). 


\section{Referencias}

1. Muñoz N, Bosch FX, de Sanjosé S, Tafur L, Izarzugaza I, Gili M, et al. The causal link between human papillomavirus and invasive cervical cancer: a population-based case-control study in Colombia and Spain. Int J Cancer. 1992;52:743-9.

2. Walboomers JM, Jacobs MV, Manos MM, Bosch FX, Kummer JA, Shah KV, et al. Human papillomavirus is a necessary cause of invasive cervical cancer worldwide. J Pathol. 1999;189:12-9.

3. Goldie SJ, Goldhaber-Fiebert JD, Garnett GP. Public health policy for cervical cancer prevention: The role of decision science, economic evaluation, and mathematical modelling. Vaccine. 2006;24(Suppl.3):S155-63.

4. Drummond M, Sculpher M, Torrance G, O'Brien B, Stoddart G. Methods for the economic evaluation of health care programmes. 3rd ed. Oxford: Oxford University Press; 2005.

5. U.S. Department of Labor. Bureau of Labor Statistics. Consumer Price Indexes. [Consultado: enero de 2006]. Disponible en: http://www.bls.gov/cpi/.

6. Goldie SJ, Freedberg KA, Weinstein MC, Wright TC, Kuntz KM. Cost effectiveness of human papillomavirus testing to augment cervical cancer screening in women infected with the human immunodeficiency virus. Am J Med. 2001;111:140-9.

7. Goldie SJ, Kuhn L, Denny L, Pollack A, Wright TC. Policy analysis of cervical cancer screening strategies in low-resource settings: Clinical benefits and cost-effectiveness. JAMA. 2001;285:3107-15.

8. Gamzu R, Almog B, Levin I, Fainaru O, Niv J, Lessing JB, et al. Clinical and economic implications of adding HPV tests to the routine cytology follow-up and management of patients with histologically defined cervical intraepithelial neoplasia grade 1. Gynecol Oncol. 2002;86:129-33.

9. Kim JJ, Wright TC, Goldie SJ. Cost effectiveness of alternative triage strategies for atypical squamous cells of undetermined significance. JAMA. 2002;287:2382-90.

10. Mandelblatt JS, Lawrence WF, Gaffikin L, Limpahayom KK, Lumbiganon $\mathrm{P}$, Warakamin $\mathrm{S}$, et al. Costs and benefits of different strategies to screen for cervical cancer in less-developed countries. J Natl Cancer Inst. 2002;94:1469-83.

11. Duttagupta C, Sengupta S, Roy M, Sengupta D, Chakraborty S, Bhattacharya $\mathrm{P}$, et al. Oncogenic human papillomavirus (HPV) infection and uterine cervical cancer: a screening strategy in the perspective of rural India. Eur J Cancer Prev. 2002;11:447-56

12. Mandelblatt JS, Lawrence WF, Womack SM, Jacobson D, Yi B, Hwang YT, et al. Benefit and costs of using $\mathrm{PVH}$ testing to screen for cervical cancer. JAMA. 2002;287:2372-81.
13. Mittendorf T, Petry KU, Iftner T, Greiner W, von der Schulenburg JM. Economic evaluation of human papillomavirus screening in Germany. Eur $\mathrm{J}$ Health Econ. 2003;4:209-15.

14. Lytwyn A, Sellors JW, Mahony JB, Daya D, Chapman W, Howard $\mathbf{M}$, et al. Adjunctive human papillomavirus testing in the 2-year follow-up of women with low-grade cervical cytologic abnormalities. A randomized trial and economic evaluation. Arch Pathol Lab Med. 2003;127:1169-75.

15. Goldie SJ, Kim JJ, Wright TC. Cost-effectiveness of human papillomavirus DNA testing for cervical cancer screening in women aged 30 years or more. Obstet Gynecol. 2004;103:619-31.

16. Sherlaw-Johnson C, Philips Z. An evaluation of liquid-based cytology and HPV testing within the UK cervical cancer screening programme. $\mathrm{Br} \mathrm{J}$ Cancer. 2004;91:84-91.

17. Kim JJ, Wright TC, Goldie SJ. Cost-effectiveness of human papillomavirus DNA testing in the United Kingdom, The Netherlands, France, and Italy. J Natl Cancer Inst. 2005;97:888-95.

18. Legood R, Gray AM, Mahe C, Wolstenholme J, Jayant $\mathrm{K}$, Nene BM, et al. Screening for cervical cancer in India: How much will it cost? A trial based analysis of the cost per case detected. Int J Cancer. 2005;117:981-7.

19. Goldie SJ, Gaffikin L, Goldhaber-Fiebert JD, Gordillo-Tobar A, Levin C, Mahé C, et al. Cost-effectiveness of cervical cancer screening in five developing countries. N Engl J Med. 2005;353:2158-68.

20. Legood R, Gray A, Wolstenholme J, Moss S. Lifetime effects, costs, and cost effectiveness of testing for human papillomavirus to manage low grade cytological abnormalities: Results of the NHS pilot studies. BMJ. 2006;332:79-85.

21. Bidus MA, Maxwell GL, Kulasingam S, Rose GS, Elkas JC, Chernofsky M, et al. Cost-effectiveness analysis of liquid-based cytology and human papillomavirus testing in cervical cancer screening. Obstet Gynecol. 2006;107:997-1005.

22. Kulasingam SL, Kim JJ, Lawrence WF, Mandelblatt JS, Myers ER, Schiffman M, et al. Cost-effectiveness analysis based on the atypical squamous cells of undetermined significance/low-grade squamous intraepithelial lesion Triage Study (ALTS). J Natl Cancer Inst. 2006;98:92-100.

23. Cuzick J, Sasieni $P$, Davies $P$, Adams J, Normand C, Frater A, et al. A systematic review of the role of human papillomavirus testing within a cervical screening programme. Health Technol Assess. 1999;3:1-196.

24. Goldie SJ. Health economics and cervical cancer prevention: a global perspective. Virus Res. 2002; 89:301-9. 
25. Goldie SJ. Chapter 15: Public health policy and costeffectiveness analysis. J Natl Cancer Inst Monogr. 2003;31:102-10.

26. Holmes J, Lindsay H, Garfield S. The cost-effectiveness of human papillomavirus screening for cervical cancer. A review of recent modelling studies. Eur $\mathrm{J}$ Health Econ. 2005;6:30-7.

27. Goldie SJ, Kim JJ, Myers E. Chapter 19: Cost-effectiveness of cervical cancer screening. Vaccine 2006;24 (Suppl. 3):S164-70.

28. Wright TC Jr, Schiffman M, Solomon D, Thomas JT, Garcia F, Goldie S, et al. Interim guidance for the use of human papillomavirus DNA testing as an adjunct to cervical cytology for screening. Obstet Gynecol. 2004;103:304-9.

29. Lörincz AT, Richart RM. Human papillomavirus DNA testing as an adjunct to cytology in cervical screening programs. Arch Pathol Lab Med. 2003;127:959-68.

30. Cuschieri KS, Cubie HA. The role of human papillomavirus testing in cervical screening. J Clin Virol. 2005;32 (Suppl. 1):S34-42.

31. Sherman ME, Lorincz AT, Scott DR, Wacholder S, Castle PE, Glass AG, et al. Baseline cytology, human papillomavirus testing, and risk for cervical neoplasia: A 10-year cohort analysis. J Natl Cancer Inst. 2003;95:46-52.

32. van den Akker-van Marle ME, van Ballegooijen M, Rozendaal L, Meijer CJ, Hebbema JD. Extended duration of the detectable stage by adding HPV test in cervical cancer screening. Br J Cancer. 2003;89:1830-3.

33. van den Akker-van Marle ME, van Ballegooijen $M$, van Oortmarssen GJ, Boer R, Habbema JD. Costeffectiveness of cervical cancer screening: Comparison of screening policies. J Natl Cancer Inst. 2002;94:193-204.

34. Kiatpongsan S, Niruthisard S, Mutirangura A, Trivijitsilp $\mathbf{P}$, Vasuratna A, Chaithongwongwatthana $\mathbf{S}$, et al. Role of human papillomavirus DNA testing in management of women with atypical squamous cells of undetermined significance. Int J Gynecol Cancer. 2006;16:262-5
35. Melnikow J, Birch S. Human papillomavirus triage of atypical squamous cells of undetermined significance: Cost-effective, but at what cost? J Natl Cancer Inst. 2006;98:82-3.

36. Kim JJ, Leung GH, Woo PP, Goldie SJ. Cost-effectiveness of organized versus opportunistic cervical cytology screening in Hong Kong. J Public Health (Oxf) 2004;26:130-7.

37. Parkin DM, Moss SM. An evaluation of screening policies for cervical cancer in England and Wales using a computer simulation model. J Epidemiol Community Health. 1986;40:143-53.

38. Koopmanshap MA, Van Oortmarssen GJ, Van Agt HM, Van Ballegooijen M, Habbema JD, Lubbe KT. Cervical cancer screening: attendance and cost-effectiveness. Inst J Cancer. 1990;45:410-5.

39. Bos AB, Van Ballegooijen M, Van Gessel-DabeKausen AA, Habbema JD. Organised cervical cancer still leads to higher coverage than spontaneous screening in the Netherlands. Eur $\mathrm{J}$ Cancer. 1998;34:1598-601.

40. Suba EJ, Murphy SK, Donnelly AD, Furia LM, Huynh ML, Raab SS. Systems analysis of real-world obstacles to successful cervical cancer prevention in developing countries. Am J Public Health. 2006;96:480-7.

41. Ministerio de Salud. Resolución 4288 de 1996, por la cual se define el Plan de Atención Básica (PAB) del Sistema General de Seguridad Social (SGSSS) y se dictan otras disposiciones. Bogotá D.C.: Ministerio de Salud de la Protección Social; 2004.

42. Profamilia. Encuesta Nacional de Demografía y Salud 2005. Bogotá: Profamilia; 2005.

43. Delgado M, Palma S. Aportaciones de la revisión sistemática y del metanálisis a la salud pública. Rev Esp Salud Pública. 2006;80:483-9.

44. Thornton A, Lee P. Publication bias in meta-analysis: Its causes and consequences. J Clin Epidemiol. 2000;53:207-16. 